\title{
THEORETICAL PREDICTIONS ON THE RESPONSE PROPERTIES OF POTENTIOMETRIC GAS SENSORS BASED ON INTERNAL POL YMER MEMBRANE ELECTRODES
}

\author{
M. E. MEYERHOFF*, Y. M. FRATICELLI, W. N. OPDYCKE, L. G. BACHAS and A. D. \\ GORDUS
}

Department of Chemistry, University of Michigan, Ann Arbor, MI 48109 (U.S A)

(Received 9th May 1983)

\section{SUMMARY}

The approprate equilibrium expressions and known thermodynamic equilibrium constants are used in calculations on the expected response properties of polymer membrane electrode-based ammonia and carbon dioxide gas sensors. Slopes, detection limits, Nernstian response ranges and selectivities of such devices are shown to be a function of the initial $\mathrm{pH}$, conic strength and equilibrium constant of the internal electrolyte buffer used within these probes. Previously reported data for an ammonia sensor of this type correlate well with the theory. The poor response characteristics of carbon dioxide sensors based on internal carbonate-responsive membranes is also explained via the model presented. Future prospects and considerations for the development of other gas sensors of this type are discussed.

Potentiometric gas sensors based on internal glass $\mathrm{pH}$ electrodes (e.g., for $\mathrm{CO}_{2}, \mathrm{NH}_{3}, \mathrm{NO}_{2}$, etc.) have become routinely used in numerous procedures for clinical and environmental analysis [1-3]. Measurements with these sensors are based on the diffusion of the analyte gas through a gas-permeable membrane into a thin film of electrolyte solution in contact with the glass $\mathrm{pH}$ electrode. The diffusing gas participates in an equilibrium reaction with the electrolyte in the thin film producing a $\mathrm{pH}$ change in this layer. Several workers have developed models for predicting the response properties of these sensors [ $4-7]$. It has been shown that the detection limits and Nernstian response ranges of these devices are dependent on the composition and concentrations of the internal electrolytes used within these probes (e.g., $\mathrm{NH}_{4} \mathrm{Cl}$ for the $\mathrm{NH}_{3}$ sensor, $\mathrm{NaHCO}_{3}$ for the $\mathrm{CO}_{2}$ sensor, etc.).

Recently, in an attempt to overcome certain limitations of the conventional gas sensors, new types of potentiometric gas probes have been developed [8-12]. These new sensors utilize internal polymeric ion-selective membrane electrodes as internal sensing elements within the traditional gas-sensing configurations. In one case, the conventional glass $\mathrm{pH}$ electrode can be replaced by an inexpensive polymer $\mathrm{pH}$-responsive membrane [11, 12], although for this approach, the response properties and selectivities of the resulting sensors are analogous to the conventional probes because the mechanism of response 
remains the same (i.e., a $\mathrm{pH}$ change in a thin electrolyte film). Alternatively, polymer ion-selective membranes responsive to equilibrium ionic forms of the analyte gases have been utilized in conjunction with internal electrolyte buffers to fabricate sensors which function via a buffer trap mechanism. For example, a nonactin-based ammonium ion-responsive polymer membrane electrode has been used as an internal element for the development of a new ammonia sensor [8]. The resulting device had improved detection limits and selectivity when compared to the conventional ammonia probes $[9,13]$. Similarly, attempts were made to develop a new carbon dioxide sensor through the use of an internal polymeric carbonate ion-selective membrane [10]. Both the ammonia and carbon dioxide sensors of this type exhibited sub-Nernstian responses and limited dynamic measuring ranges with the overall response propertics being largely dependent on the choice of the internal electrolyte buffer.

The purpose of this paper is to present an equilibrium model which can be used to predict accurately the response properties of these new types of sensors with regard to expected slopes, detection limits, Nernstian response ranges, etc. Calculations are made for a variety of internal electrolyte buffers that have been used in the past as well as for some not previously evaluated. For carbon dioxide and ammonia sensors, it will be shown that the choice of internal electrolyte buffer dramatically affects the behavior of the sensors and that predicted response properties for each buffer correlate with previously reported observations. Prospects for improving the response of the carbon dioxide sensor as well as for preparing other sensors of this type will also be discussed.

\section{THE EQUILIBRIUM MODEL}

Figure 1(a) shows a general schematic view of the type of gas sensor for which calculations are made. Figure 1 (b) shows expanded views of the $\mathrm{CO}_{2}$ and $\mathrm{NH}_{3}$ sensors along with the pertinent reactions which take place within the sensing tips of these probes. These sensors initially contain an internal electrolyte buffer system, $\mathrm{B} / \mathrm{BH}^{+}$(referring to the free base form, $\mathrm{B}$, and the protonated form, $\mathrm{BH}^{+}$, of the buffer reagent, e.g., tris(hydroxymethyl)aminomethane (Tris), etc.). The ratio of these two species in the thin film electrolyte controls the initial $\mathrm{pH}$ of the buffer in the sensing layer.

In order to predict the Nernstian response ranges, slopes, selectivities, and detection limits of these sensors, it is necessary to derive expressions which will evaluate the $\mathrm{pH}$ of the thin buffer film as a function of the dissolved gas concentration in the sample. Alternatively, an expression which evaluates the concentration of gas required in the sample to attain a given $\mathrm{pH}$ in the thin film could also be used. To derive the required expressions, it is necessary to make the following five assumptions about the equilibrium models shown in Fig. 1(b). First, it is assumed that the rate of species exchange between the bulk reservoir of internal electrolyte buffer and the thin film is very slow 
a)

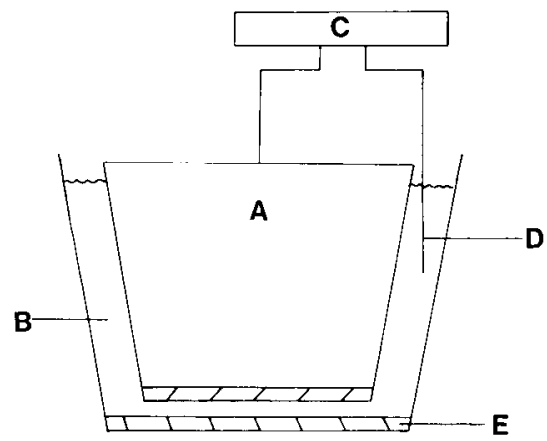

b)

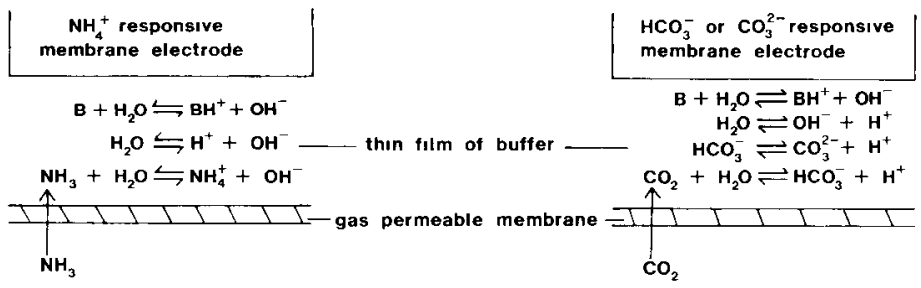

Fig.1. (a) Schematic diagram of polymer membrane electrode-based potentıometric gas sensor: (A) internal polymer membrane ion-selective electrode, (B) reservoir of internal electrolyte buffer, (C) $\mathrm{pH}$ meter, (D) $\mathrm{Ag} / \mathrm{AgCl}$ reference electrode; (E) outer gas-permeable membrane (silicone rubber for $\mathrm{CO}_{2}$ sensor, polytetrafluoroethylene for $\mathrm{NH}_{3}$ sensor). (b) Expanded views of new ammonia and carhon dioxıde sensors and their associated chemical equilibria.

relative to the rate of gas diffusion into the thin film of buffer and the rates associated with equilibrium reactions in that layer. Thus the thin film is considered to be an essentially isolated small volume of buffer with which the sample gas is in equilibrium, the junction between the internal reservoir of buffer and the thin film merely serving as a point of electrolytic contact between the two solutions.

Second, the Henry constants $\left(K_{\mathrm{H}}\right)$ for the dissolved gases are assumed to be equal on both sides of the gas-permeable membrane so that at equilibrium, i.e., when the partial pressure of gas is equal on both sides of the gas-permeable membrane, the concentration of dissolved gas will be equal. Th1s will be true if the sample and internal buffer solutions have similar ionic strengths and osmolarities. Third, it is assumed that the osmolarities of the sample and internal buffer solutions are indeed very similar so that diffusion of watcr vapor across the gas-permeable membrane will not dilute or concentrate the ionic strength of the internal electrolyte buffer film.

Fourth, the thin film of buffer is assumed to be an extremely small volume relative to the possible sample volumes into which these sensors are placed. Therefore, the sample can be considered an unlimited sink of analyte gas, and, at equilıbrium, the concentration of gas in the thin film will be exactly 
the same as in the sample volume. Thus, in setting up equilibrium expressions regarding the hydrolysis of the analyte gas, the sample gas concentration value is used, not that value minus the amount ionized by the hydrolysis reaction.

The fifth assumption is that for any sample gas concentration, equilibration of the gas with the thin film buffer does not significantly alter the total ionic strength of this aqueous layer. Consequently, the same conditional equilibrium constants can be utilized throughout the gas concentration range considered. It will be shown that this assumption is not always valid for the $\mathrm{CO}_{2}$ sensor.

For the ammonia sensor model depicted in Fig. 1(b), the $\mathrm{pH}$ of the buffer film is initially governed by the buffer equilibrium reaction and the dissociation of water:

$\mathrm{B}+\mathrm{H}_{2} \mathrm{O} \rightleftharpoons \mathrm{BH}^{+}+\mathrm{OH}^{-} ; \mathrm{H}_{2} \mathrm{O} \rightleftharpoons \mathrm{H}^{+}+\mathrm{OH}^{-}$

At equilibrium,

$K_{\mathrm{b}(\mathrm{B})}=\left(\left(\left[\mathrm{BH}^{+}\right]_{\mathrm{s}}+\left[\mathrm{BH}^{+}\right]_{10 n z}\right)\left[\mathrm{OH}^{-}\right]\right) /\left([\mathrm{B}]_{\mathrm{s}}-\left[\mathrm{BH}^{+}\right]_{\text {Ionz }}\right)$

where $K_{\mathrm{b}(\mathrm{B})}$ is the conditional ionization constant for the weak base buffer reagent $\mathrm{B},\left[\mathrm{BH}^{+}\right]_{s}$ and $[\mathrm{B}]_{s}$ are the starting concentrations of the protonated buffer and free base buffer reagent, respectively, $\left[\mathrm{BH}^{+}\right]_{\text {1on } /}$ is the concentration of protonated buffer formed from hydrolysis of the given starting concentration of $\mathrm{B}$, and $[\mathrm{OH}]$ represents the hydroxide ion concentration in the thin film at equilibrium.

Solving Eqn. (1) for $\left[\mathrm{BH}^{+}\right]_{\text {onuz }}$ yields

$\left[\mathrm{BH}^{+}\right]_{\text {onuz }}=\left([\mathrm{B}]_{\mathrm{s}} K_{\mathrm{b}(\mathrm{B})}-\left[\mathrm{BH}^{+}\right]_{\mathrm{s}}\left[\mathrm{OH}^{-}\right]\right) /\left(K_{\mathrm{b}(\mathrm{B})}+\left[\mathrm{OH}^{-}\right]\right)$

In the presence of ammonia gas, a simultaneous weak base hydrolysis reaction occurs in the buffer film: $\mathrm{NH}_{3}+\mathrm{H}_{2} \mathrm{O} \rightleftharpoons \mathrm{NH}_{4}^{+}+\mathrm{OH}^{-}$. Because at equilibrium, $\left[\mathrm{NH}_{3}\right]_{\text {sam ple }}=\left[\mathrm{NH}_{3}\right]_{\mathrm{film}}$ (as assumed above), the equilibrium constant for this reaction can be written as follows

$\left.K_{\text {b(NH }}\right)=\left(\left[\mathrm{NH}_{4}^{+}\right]\left[\mathrm{OH}^{-}\right]\right) /\left[\mathrm{NH}_{3}\right]_{\text {sam ple }}$

If, for example, hydrochloric acid is used initially to prepare the buffer reagent, then the charge-balance equation for these simultaneous hydrolysis reactions can be implemented as follows:

$\left[\mathrm{H}^{+}\right]+\left[\mathrm{NH}_{4}^{+}\right]+\left[\mathrm{BH}^{+}\right]_{\mathrm{s}}+\left[\mathrm{BH}^{+}\right]_{1 \mathrm{oniz}}=\left[\mathrm{Cl}^{-}\right]_{\mathrm{s}}+\left[\mathrm{OH}^{-}\right]$

Because $\left[\mathrm{BH}^{+}\right]_{\mathrm{s}}=\left[\mathrm{Cl}^{-}\right]_{s}$, Eqn. (4) can be written as

$\left[\mathrm{OH}^{-}\right]-\left[\mathrm{H}^{+}\right]=\left[\mathrm{BH}^{+}\right]_{\text {lone }}+\left[\mathrm{NH}_{4}^{+}\right]$

Solving Eqn. (3) for $\left[\mathrm{NH}_{4}^{+}\right]$and substituting that expression along with $\left[\mathrm{B}^{+}\right]_{10 n}$ (Eqn. 2) into Eqn. (5) (also for notational simplicity, writıng $\left[\mathrm{BH}^{+}\right]$ $=\left[\mathrm{BH}^{+}\right]_{\mathrm{s}}$ and $\left.K_{\mathrm{w}} /\left[\mathrm{OH}^{-}\right]=\left[\mathrm{H}^{+}\right]\right)$yields

$\left[\mathrm{OH}^{-}\right]-\left(K_{\mathrm{w}} /\left[\mathrm{OH}^{-}\right]\right)=\left\{\left([\mathrm{B}] K_{\mathrm{b}(\mathrm{B})}-\left[\mathrm{BH}^{+}\right]\left[\mathrm{OH}^{-} 1\right) /\left(K_{\mathrm{h}(\mathrm{B})}+\left[\mathrm{OH}^{-}\right]\right)\right\}\right.$

$+\left\{\left(\left[\mathrm{NH}_{3}\right]_{\text {sample }} K_{\mathrm{b}\left(\mathrm{NH}_{3}\right)}\right) /\left[\mathrm{OH}^{-}\right]\right\}$ 
It is much easier to solve Eqn. (6) for $\left[\mathrm{NH}_{3}\right]_{\text {sample }}$ as a function of $\left[\mathrm{OH}^{-}\right]$ rather than for $\left[\mathrm{OH}^{-}\right]$as a function of $\left[\mathrm{NH}_{3}\right]_{\text {sample }}$. Such treatment results in

$$
\begin{aligned}
& {\left[\mathrm{NH}_{3}\right]_{\text {sample }}=\left\{\left[\mathrm{OH}^{-}\right]^{3}+\left[\mathrm{OH}^{-}\right]^{2}\left(K_{\mathrm{b}(\mathrm{B})}+\left[\mathrm{BH}^{+}\right]\right)-\left[\mathrm{OH}^{-}\right]\left(K_{\mathrm{w}}+[\mathrm{B}] K_{\mathrm{b}(\mathrm{B})}\right)\right.} \\
& \left.-K_{\mathrm{w}} K_{\mathrm{b}(\mathrm{B})}\right\} /\left\{\left[\mathrm{OH}^{-}\right] K_{\mathrm{b}\left(\mathrm{NH}_{3}\right)}+K_{\mathrm{b}(\mathrm{B})} K_{\mathrm{b}\left(\mathrm{NH}_{3}\right)}\right\}
\end{aligned}
$$

In an analogous manner, the model depicted in Fig. 1(b) for the carbon dioxide sensor can be utilized to derive the expression necessary to determine the sample $\mathrm{CO}_{2}$ concentration required to attain a given $\mathrm{pH}$ value in the thin buffer film of the new probe. Equation (8) is the result of such a derivation:

$$
\begin{gathered}
{\left[\mathrm{CO}_{2}\right]_{\text {sample }}=\left\{\left[\mathrm{H}^{+}\right]-\left(K_{\mathrm{w}} /\left[\mathrm{H}^{+}\right]\right)+\left(\left(K_{\mathrm{b}(\mathrm{B})}[\mathrm{B}]\left[\mathrm{H}^{+}\right]-\left[\mathrm{BH}^{+}\right] K_{\mathrm{w}}\right) /\right.\right.} \\
\left.\left.\left(K_{\mathrm{w}}+K_{\mathrm{b}(\mathrm{B})}\left[\mathrm{H}^{+}\right]\right)\right)\right\} /\left\{\left(K_{1} /\left[\mathrm{H}^{+}\right]\right)+\left(2 K_{1} K_{2} /\left[\mathrm{H}^{+}\right]^{2}\right)\right\}
\end{gathered}
$$

where $K_{1}$ and $K_{2}$ are first and second conditional dissociation constants of carbonic acid. For a given sample $\mathrm{CO}_{2}$ concentration and thin-film $\mathrm{pH}$ value, the equilibrium thin-film concentrations of hydrogencarbonate and carbonate lons can be calculated from the following equations:

$\left[\mathrm{CO}_{3}^{2-}\right]_{\mathrm{fl} l \mathrm{~m}}=K_{1} K_{2}\left[\mathrm{CO}_{2}\right]_{\text {sam ple }} /\left[\mathrm{H}^{+}\right]^{2}$

and

$\left[\mathrm{HCO}_{3}^{-}\right]_{\mathrm{f} 1 \mathrm{~m}}=K_{1}\left[\mathrm{CO}_{2}\right]_{\text {sample }} /\left[\mathrm{H}^{+}\right]$

In order to evaluate Eqns. (7) and (8) for various buffer reagents, each having different initial $\mathrm{pH}$ values and ionic strengths, it is necessary to use conditional equilibrium constants in the calculations, because Eqns. (7) and (8) are derived in concentration terms rather than activities. In general, for any equilibrium reaction, e.g., $\mathrm{A}+\mathrm{H}_{2} \mathrm{O} \rightleftharpoons \mathrm{B}+\mathrm{C}$, the conditional constant can be readily determined from the known thermodynamic constant via the equation $K_{\text {cond }}=K_{\text {therm }} / K_{\gamma}$, where $K_{\text {therm }}=a_{\mathrm{B}} a_{\mathrm{C}} / a_{\mathrm{A}}=\gamma_{\mathrm{B}}[\mathrm{B}] \gamma_{\mathrm{C}}[\mathrm{C}] / \gamma_{\mathrm{A}}[\mathrm{A}]$, and $K_{\gamma}=\gamma_{\mathrm{B}} \gamma_{\mathrm{C}} / \gamma_{\mathrm{A}}$; here $a$ represents activities of species and $\gamma$ is the activity coeffrcient for the species. Therefore, for each internal buffer solution considered, activity coefficients for all species must be calculated by the extended Debye-Huckel equation [14] before evaluating the conditional equilibrium constants for the buffer system as well as for the dissolved analyte gases (i.e., $K_{1}$ and $K_{2}$ for the $\mathrm{CO}_{2}$ sensor, and $K_{\left.\mathrm{b} \mathrm{NH}_{3}\right)}$ for the $\mathrm{NH}_{3}$ probe). Similarly, the dissociation constant for water $\left(K_{\mathrm{w}}\right)$ must also be corrected for ionic strength effects. 'T'able 1 summarizes some of the conditional constants utilized in this report for theoretical calculations involving different internal buffer reagents and their associated ionic strengths.

While assumptions could be made to simplify Eqns. (7) and (8), the use of a microcomputer (Commodore, model 8032) allows for the strict evaluation of each equation. Programs were written which allowed conditional constants, initial $\mathrm{pH}$ values, ionic strengths, required activity coefficients, etc., to be 


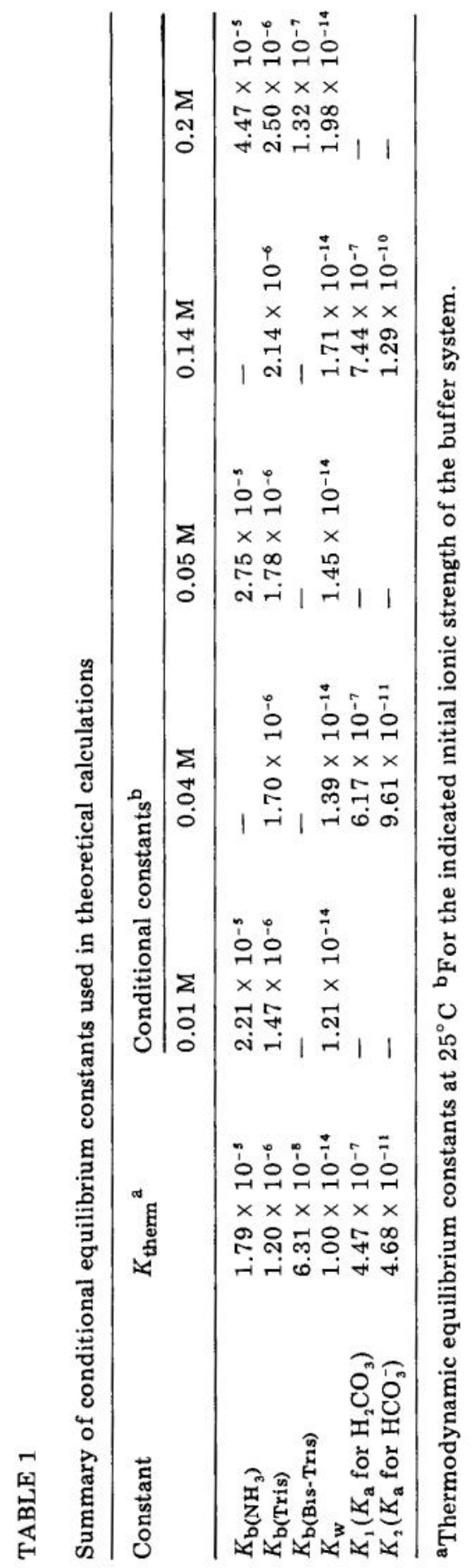


entered into the microcomputer. Based on these initial values for a given buffer reagent, the computer determined $[B]$. An iteration part of the program then evaluated Eqns. (7) or (8) for continuously increasing (for ammonia system) or decreasing (for carbon dioxide system) thin-film $\mathrm{pH}$ values and all concentration data were output to a printer (Centronics, model 739). For each iteration, the $\mathrm{pH}$ was changed by \pm 0.001 units to generate the theoretical plots.

\section{RESULTS AND DISCUSSION}

\section{Ammonia sensor}

Figure 2 shows the computer-generated plots of the thin-film $\mathrm{pH}$ as a function of sample ammonia concentration for five different internal Tris $-\mathrm{HCl}$ buffer reagents. It can be seen that the internal solutions in which the initial $\mathrm{pH} \approx \mathrm{p} K_{\mathrm{a(B)}}$ (i.e., $\mathrm{pH} 8.0$ or $\mathrm{pH} 8.3$ ) offer the best buffering ability towards increasing sample ammonia concentrations and allow the use of less concentrated (lower ionic strength) buffers. For solutions in which the initial $\mathrm{pH}$ differs significantly from the $\mathrm{p} K_{\mathrm{a}(\mathrm{B})}$ and $\mathrm{p} K_{\mathrm{a}\left(\mathrm{NH}_{3}\right)}$ (i.e., $\mathrm{pH} 7.50$ buffers), the ionic strength of the buffer has a greater effect on maintaining the initial $\mathrm{pH}$ of the thin-film electrolyte layer of the sensor. In previous work [13], experi-
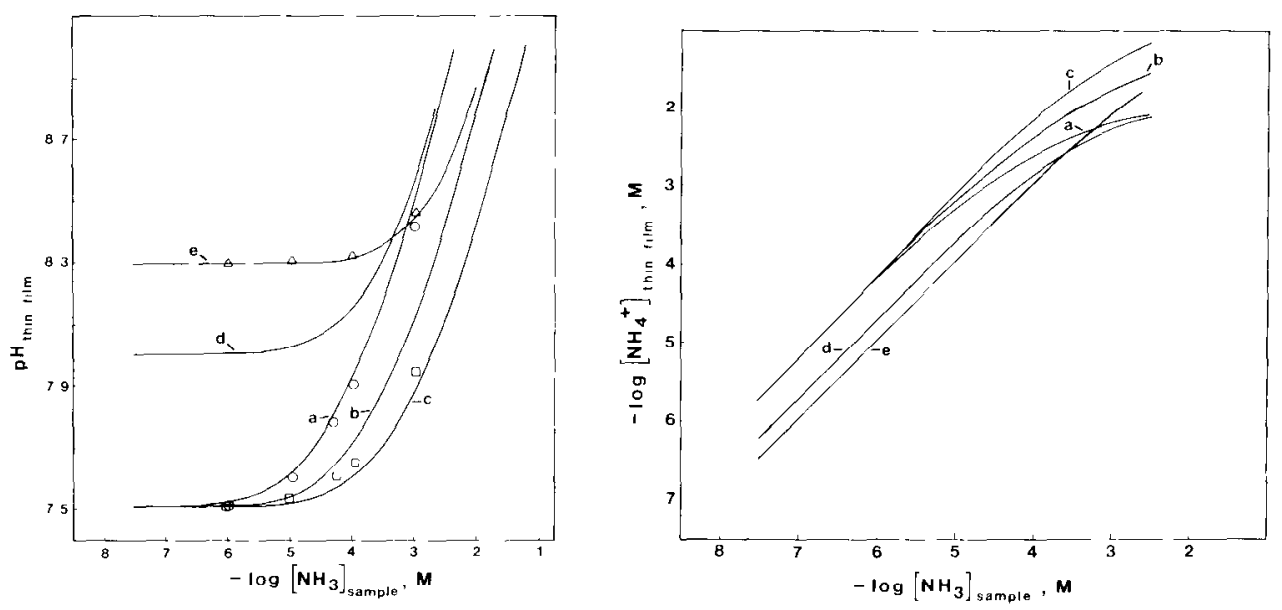

Fig. 2. Computer-generated plots of thin-film $\mathrm{pH}$ vs. sample ammonia concentration for new ammonia sensor prepared with various internal buffer solutions $\cdot$ (a) $0.01 \mathrm{M}$ Tris $-\mathrm{HCl}$, pH 7.50; (b) $0.05 \mathrm{M}$ Tris-HCl, pH 7.50; (c) $0.20 \mathrm{M}$ Tris-HCl, pH 7.50,(d) $0.01 \mathrm{M}$ Tris$\mathrm{HCl}, \mathrm{pH} 8.00$, (e) $0.05 \mathrm{M}$ Tris- $\mathrm{HCl}, \mathrm{pH} 8.30$; (concentrations of buffers refer to total ionic strength of buffer solution which is due solely to the presence of $\mathrm{Tris}^{+}$and $\mathrm{Cl}^{-}$ions.) Also shown are experımental results taken from $[13](\triangle) 0.05 \mathrm{M} \mathrm{Tris}-\mathrm{HCl}, \mathrm{pH} 8.30,(\circ) 0.01 \mathrm{M}$ Tris- $\mathrm{HCl}, \mathrm{pH} 7.50,(\mathrm{o}) 0.1 \mathrm{C}$ M Tris--HCl, pH 7.50 (computer plot not shown).

Fig. 3. Computer plots of equilibrium thin-film ammonium ion concentration vs. sample ammonia concentration for the same five buffers $(a-e)$ shown in Fig. 2. 
ments were conducted actually to measure the thin-film $\mathrm{pH}$ as a function of the sample gas concentration for several of the buffers and the results of those experiments are also shown in Fig. 2. There is good correlation between the experimentally observed values and those predicted by the equilibrium model.

As can be seen in Fig. 3, the ability to maintain a constant $\mathrm{pH}$ in the thin film will ultimately determine the Nernstian response range of the sensor. This figure shows the plots of equilibrium thin-film ammonium ion concentration as a function of sample gas concentration for the same five Tris- $\mathrm{HCl}$ buffers considered in Fig. 2. It is apparent that for internal reagents with greater buffer capacity, an improved linear range of $\log \left[\mathrm{NH}_{4}^{+}\right]_{\text {film }}$ vs. $\log$ $\left[\mathrm{NH}_{3}\right]_{\text {sam ple }}$ plots result. It is, however, evident that a lower initial $\mathrm{pH}$ value for the internal buffer reagent is desirable to improve detection limits because more ammonium ions are formed in the film for a given concentration of dissolved gas (i.e., improved buffer trap effect). It should be noted that Tris$\mathrm{HCl}$ buffers were evaluated in these calculations because previous experiments $[8,9]$ demonstrated that this buffer is the optimum choice among common buffering systems. This is primarily because the internal nonactin-based polymer ammonium electrode lacks selectivity over many common cationic buffer components, e.g., potassium, sodium, etc., and the presence of these species in the internal electrolyte would diminish the detection capabilities of the sensor.

From Fig. 3, it is a simple matter to predict the slopes and logarithmic response ranges of ammonia gas sensors prepared with the various Tris- $-\mathrm{HCl}$ buffers. Because the internal ammonium responsive electrode responds in a Nernstian fashion toward ammonium ion activity in the thin buffer film,

$E_{\text {cell }}=K+0.059 \log \left(\gamma_{\mathrm{NH}_{4}^{\prime}}\left[\mathrm{NH}_{4}^{+}\right]\right)$

and because for a satisfactory ammonia gas sensor, the potentiometric response should be expressed by the equation

$E_{\text {cell }}=K+S \log \left[\mathrm{NH}_{3}\right]_{\text {sample }}$

where $S$ is the operational slope of the sensor, then for Eqns. (12) and (11), respectively,

$S=\mathrm{d} E_{\text {cell }} / \mathrm{d} \log \left[\mathrm{NH}_{3}\right]_{\text {sample }}$

and

$\mathrm{d} E_{\text {cell }}=0.059 \mathrm{dlog}\left(\gamma_{\mathrm{NH}_{4}^{+}}\left[\mathrm{NH}_{4}^{+}\right]\right)$

Substitution of $\mathrm{d} E_{\text {cell }}$ in Eqn. (13) yields the following expression for the slope of the gas sensor:

$S=0.059 \mathrm{dlog}\left(\gamma_{\mathrm{NH}_{4}^{+}}\left[\mathrm{NH}_{4}^{+}\right]\right) / \operatorname{dlog}\left[\mathrm{NH}_{3}\right]_{\text {sample }}$

Because $\gamma_{\mathrm{NH}_{4}^{+}}$is constant for a given ionic strength internal buffer, the slopes of the curves shown in Fig. 3 multiplied by $0.059 \mathrm{~V}$ will give the theoretical 
slopes of the gas sensors. As can be seen in Fig. 3, the log- log plots rapidly become non-linear at higher ammonia gas concentrations because of the $\mathrm{pH}$ change within the buffer film. Indeed, Table 2 lists the predicted slopes for decade ranges of sample ammonia concentrations. The sub-Nernstian response properties, even at extremely low concentrations of ammonia (i.e., $10^{-7}-$ $10^{-6} \mathrm{M}$ ), for gas sensors prepared with low ionic strength buffers (e.g., $0.01 \mathrm{M}$ Tris- $-\mathrm{HCl}$ ) fit well with what has been observed experimentally [8, 9]. Perfectly Nernstian response slopes for low ammonia concentrations are predicted for the internal buffer solutions having greater buffer capacities, although in practice this is seldom the case because the internal nonactin polymer membrane electrode often exhibits slightly sub-Nernstian response (i.e., $55-58 \mathrm{mV} /$ decade) toward ammonium ions. Indeed, the operational slopes of the final sensors can never exceed that of the internal sensing element. As can be seen in Table 2, near-Nernstian behavior can be extended up to $10^{-4} \mathrm{M}$ ammonia when a $0.05 \mathrm{M}$ Tris $-\mathrm{HCl} \mathrm{pH} 8.30$ buffer is used and even to higher sample ammonia concentrations when buffers with higher ionic strengths are used. In principle, it would take an extremely concentrated buffer reagent to obtain Nernstian response above $10^{-3} \mathrm{M}$ ammonia. Therefore, conventional types of sensors are recommended for such measurements.

Whereas increasing the ionic strength of the internal buffer improves the Nernstian range for the new ammonia sensor, these improved slopes come at the expense of absolute detection limits. There are two reasons for this effect. First, the detection limits of the sensor will be partly dependent on the innate detection limits of the nonactin membrane electrode toward ammonium ions formed in the thin buffer film. Increasing the ionic strength of the buffer will also increase the concentration of protonated Tris $^{+}$ions $\left(\mathrm{BH}^{+}\right)$in the film. Although the nonactin-based membrane displays only

\section{TABLE 2}

Predicted slopes for new ammonia sensors prepared with Tris-HCl internal buffer solutions of different strengths and $\mathrm{pH}^{\mathrm{a}, \mathrm{b}}$

\begin{tabular}{llllll}
\hline $\begin{array}{l}\text { Sample } \mathrm{NH}_{3} \\
\text { concentration } \\
\text { range }\end{array}$ & \multicolumn{5}{l}{ Slopes $(\mathrm{mV} /$ decade $)$} \\
\cline { 2 - 6 }$(\mathrm{M})$ & $\begin{array}{l}0.01 \mathrm{M} \\
\mathrm{pH} 7.50\end{array}$ & $\begin{array}{l}0.05 \mathrm{M} \\
\mathrm{pH} 7.50\end{array}$ & $\begin{array}{l}0.20 \mathrm{M} \\
\mathrm{pH} 7.50\end{array}$ & $\begin{array}{l}0.01 \mathrm{M} \\
\mathrm{pH} 8.00\end{array}$ & $\begin{array}{l}0.05 \mathrm{M} \\
\mathrm{pH} 8.30\end{array}$ \\
\hline $10^{-7}-10^{-6}$ & 57 & 59 & 59 & 59 & 59 \\
$10^{-6}-10^{-5}$ & 54 & 57 & 58 & 58 & 59 \\
$10^{-5}-10^{-4}$ & 40 & 50 & 55 & 52 & 58 \\
$10^{-4}-10^{-3}$ & 25 & 34 & 42 & 34 & 53 \\
\hline
\end{tabular}

a Slopes determined from least-squares fit of computer-generated $\log \left[\mathrm{NH}_{4}^{+}\right]_{\text {film }}$ vs. $\log$ $\left[\mathrm{NH}_{3}\right]_{\text {sample }}$ data points for given ammonia concentration range. ${ }^{b}$ Values given assume that the internal nonactin polymer membrane electrode has Nernstian response of $59 \mathrm{mV} /$ decade towards ammonium ion activities. 
minimal response to Tris ${ }^{+}$, there is indeed some finite response and the selectivity of the membrane over $\mathrm{Tris}^{+}$can be evaluated from the Nicolsky equation:

$E=K+0.059 \log \left(a_{\mathrm{NH}_{4}^{+}}+k a_{\mathrm{Trus}^{+}}\right)$

The selectivity coefficient, $k$, was found to be about $10^{-5}$; however, even with this high degree of selectivity, any increase in $\mathrm{Tris}^{+}$levels will diminish the ability to sense extremely low levels of ammonium ions in the buffer film. Secondly, because the nonactin polymer membrane electrode actually responds to the activity of ammonium ions in the thin film, any increase in the ionic strength of the buffer above $0.1 \mathrm{M}$ will rapidly decrease the $a_{\mathrm{NH}_{4}^{+}}$ for a given sample gas concentration, thereby reducing the detection capabilities of the sensor. In practice, when low ionic strength buffers with low initial $\mathrm{pH}$ values $(\mathrm{pH} 7.50)$ are used, atmospheric levels of ammonia and ammonia impurities in the reagents used to evaluate the sensors (e.g., sodium hydroxide sample solutions to generate ammonia gas) appear to determine the detection limits of the new ammonia sensor. For example, normal atmospheric levels of ammonia in equilibrium with a sodium hydroxide solution will produce a background level of $10^{-8}-5 \times 10^{-7} \mathrm{M}$ ammonia in the test solution [1, 15]. Thus, for an internal buffer of $0.01 \mathrm{M}$ Tris $-\mathrm{HCl}, \mathrm{pH} 7.50$, examination of Fig. 3 shows that between $10^{-6}$ and $5 \times 10^{-5} \mathrm{M}$ ammonium ions are formed in the thin film when in total equilibrium with the atmosphere. These ammonium ion concentrations are well within the detection limits of the nonactin-based polymer electrode under these low ionc strength conditions [8].

The selectivity of the new ammonia sensor has previously been studied with regard to volatile amine interferences [13]. It was found experimentally that the degree of selectivity depends on the buffering strength of the internal buffer reagent. Indeed, these substances interfere with the response by diffusing across the gas-permeable membrane and altering the $\mathrm{pH}$ of the buffer film in much the same manner as high ammonia gas concentrations change the $\mathrm{pH}$ of the film (see Fig. 1). Because the internal nonactin-based membrane electrode has only minimal response to protonated forms of the amines [13], only a negative interference in the measurement of ammonia is possible when volatile amines are present in a sample (1.e., interfering amines make the film $\mathrm{pH}$ higher, thereby decreasing the equilibrium concentration of ammonium ions formed from the analyte). Thus, as is the case for improving slopes and linear response ranges, high ionic strength buffers with $\mathrm{pH}$ values at or near the $\mathrm{p} K_{\mathrm{b}}$ of the buffer base are desirable for decreasing the negative interferences caused by volatile amines. To actually determine the effect of amine concentrations on the $\mathrm{pH}$ of the thin buffer film, Eqn. (7) can be evaluated using the appropriate $K_{\mathrm{b}}$ values for the given amines rather than $K_{\mathrm{b}}$ for ammonia.

\section{Carbon dioxide sensors}

Figure 4 shows the computer-generated data for thin-film $\mathrm{pH}$ values as a function of sample gas concentration for new $\mathrm{CO}_{2}$ sensors depicted in 
Fig. 1(b). Plots are presented for sensors prepared with three different internal buffer reagents. Figure 5 shows how equilibrium thin-film carbonate and hydrogencarbonate ion concentrations change as the sample $\mathrm{CO}_{2}$ concentration increases for these three internal reagents. The same generalizations made for the ammonia sensor can also be made for the carbon dioxide sensor. As sample $\mathrm{CO}_{2}$ concentrations increase, the $\mathrm{pH}$ of the buffer film decreases. If the buffer film has an initially high $\mathrm{pH}$ value (e.g., 8.75), which is required to produce significant quantities of carbonate from diffusing $\mathrm{CO}_{2}$ (this is the case when a carbonate-selective polymer electrode is used as the internal sensing element), then the $\mathrm{pH}$ decreases rapidly over the entire $\mathrm{CO}_{2}$ concentration range evaluated (see Fig. 4). This is because there is a relatively large difference between the initial buffer $\mathrm{pH}(8.75)$ and the acidity constant for carbonic acid $\left(\mathrm{p} K_{\mathrm{a}}\right.$ 6.6). Increasing the ionic strength of the internal buffer

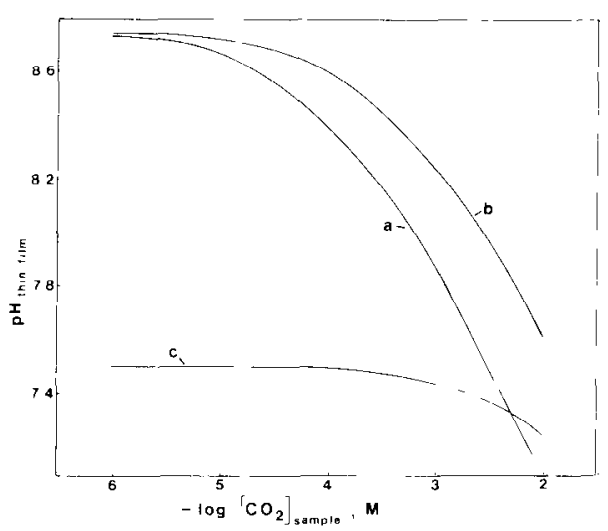

Fig 4. Computer-generated plots of equilibrium thin-film pH vs. sample carbon dioxide concentration for new carbon dioxide sensors prepared with various internal buffer solutions: (a) $0.04 \mathrm{M}$ Tris $-\mathrm{H}_{2} \mathrm{SO}_{4}, \mathrm{pH} 8.75$; (b) $0.14 \mathrm{M}$ Tris $-\mathrm{H}_{2} \mathrm{SO}_{4}, \mathrm{pH} 8.75$; (c) $0.20 \mathrm{M}$ BisTris- $\mathrm{HCl}, \mathrm{pH} 7.50$ (concentrations of buffers refer to total ionic-strengths).
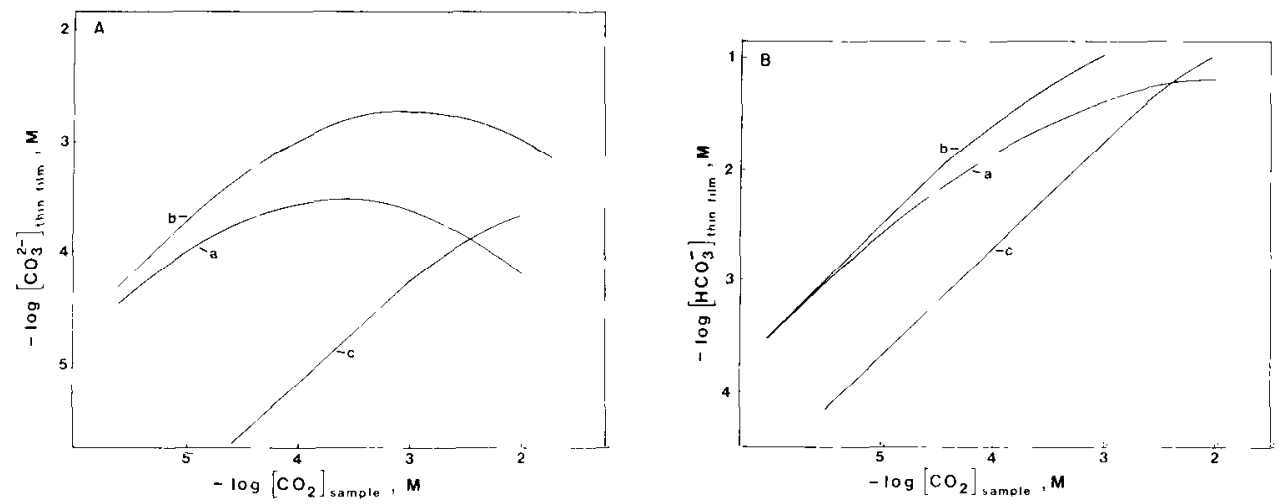

Fig. 5. Computer plots of equilibrium thin-film concentrations of (A) carbonate and (B) hydrogencarbonate vs. sample carbon dioxide concentration for the same three buffers shown in Fig. 4, (a-c) refer to Fig. 4. 
(e.g., from $0.04 \mathrm{M}$ to $0.14 \mathrm{M}$, decreases the degree of $\mathrm{pH}$ change in the film; however, even relatively high ionic strength buffers (e.g., $0.50 \mathrm{M}$ ) do not eliminate this effect over the typical concentration range of $\mathrm{CO}_{2}$ measurements (data not shown in figures). If, however, the internal buffer system is changed to one with a lower $\mathrm{p} K_{\mathrm{a}}$ value, e.g., 1,3-bis-[tris(hydroxymethyl)methylamino] propane (Bis-Tris) and the initial $\mathrm{pH}$ of the buffer is lowered to 7.50 , the magnitude of the $\mathrm{pH}$ change in the thin film is greatly reduced (see Fig. 4).

The data presented in Fig. 4 support the observations made previously when a carbonate-selective polymer membrane was utilized as an internal element for a new $\mathrm{CO}_{2}$ sensor [10]. In that work, it was reported that such a sensor, when prepared with a Tris $-\mathrm{H}_{2} \mathrm{SO}_{4}$ buffer, $\mathrm{pH} 8.75$ (0.1 M with regard to total Tris, $0.04 \mathrm{M}$ ionic strength), as the internal solution, had negligible response toward dissolved $\mathrm{CO}_{2}$. When the buffer capacity of the internal reagent was increased ( $0.5 \mathrm{M}$ with respect to total Tris, $0.14 \mathrm{M}$ ionic strength), logarithmic response toward $\mathrm{CO}_{2}$ was obtained between $3 \times 10^{-5}$ and $3 \times$ $10^{-4} \mathrm{M} \mathrm{CO} \mathrm{CO}_{2}$, although the slope of this response was sub-Nernstian (15-20 mV/decade). Above $5 \times 10^{-4} \mathrm{M} \mathrm{CO}_{2}$, the response completely leveled off and actually reversed in direction [10]. Examination of Fig. 5A explains these results. Predicted slopes based on the $\log \left[\mathrm{CO}_{3}^{2-}\right]_{\text {film }}$ vs. $\log \left[\mathrm{CO}_{2}\right]_{\text {sample }}$ plots for both pH 8.75 buffers are sub-Nernstian over the $10^{-5}-10^{-4} \mathrm{M} \mathrm{CO}_{2}$ concentration range (see Table 3). At higher analyte concentrations, equilibrium carbonate concentrations actually decrease in the thin film because of the large $\mathrm{pH}$ change. This fact is reflected in the positive slopes listed in Table 3 for the carbonate electrode-based $\mathrm{CO}_{2}$ sensor at $\mathrm{CO}_{2}$ concentrations $>10^{-3} \mathrm{M}$. As can be seen in Fig. $5 \mathrm{~A}$ and Table 3, when a low initial pH buffer system (Bis-Tris, pH 7.50) with a relatively high ionic strength is utilized internally, the situation improves dramatically with regard to

\section{TABLE 3}

Predicted slopes for new carbon dioxıde sensors prepared with various internal buffer solutions and polymer membrane electrodes ${ }^{a}$

\begin{tabular}{|c|c|c|c|c|c|c|}
\hline \multirow{4}{*}{$\begin{array}{l}\text { Sample } \mathrm{CO}_{2} \\
\text { concentration } \\
\text { range (M) }\end{array}$} & \multicolumn{6}{|c|}{ Slopes (mV/decade) } \\
\hline & \multicolumn{3}{|c|}{ Internal $\mathrm{CO}_{3}^{2-}$ electrode ${ }^{\mathrm{b}}$} & \multicolumn{3}{|c|}{ Internal $\mathrm{HCO}_{3}^{-}$electrode $\mathrm{e}^{\mathrm{c}}$} \\
\hline & \multicolumn{2}{|c|}{$\mathrm{Trus}-\mathrm{SO}_{4}, \mathrm{pH} 8.75$} & \multirow{2}{*}{$\begin{array}{l}\text { Bis-Tris-HCl, } \\
\text { pH } 7.50,0.20 \mathrm{M}\end{array}$} & \multicolumn{2}{|c|}{ Trus-SO $\mathrm{SO}_{4}$ pH 8.75} & \multirow{2}{*}{$\begin{array}{l}\text { B1s-Tris-HCl, } \\
\text { pH } 7.50,0.20 \mathrm{M}\end{array}$} \\
\hline & $004 \mathrm{M}$ & $0.14 \mathrm{M}$ & & $0.04 \mathrm{M}$ & $0.14 \mathrm{M}$ & \\
\hline $\begin{array}{l}10^{-5}-10^{-4} \\
10^{-4}-10^{-3} \\
10^{-3}-10^{-2}\end{array}$ & $\begin{array}{r}-13 \\
+2 \\
+17\end{array}$ & $\begin{array}{r}-21 \\
-7 \\
+8\end{array}$ & $\begin{array}{l}-29 \\
-27 \\
-17\end{array}$ & $\begin{array}{l}-43 \\
-28 \\
-12\end{array}$ & $\begin{array}{l}-52 \\
-37 \\
-21\end{array}$ & $\begin{array}{l}-58 \\
-56 \\
-47\end{array}$ \\
\hline
\end{tabular}

${ }^{a}$ Slopes determined from least-squares fit of computer-generated log $\left[\mathrm{CO}_{3}^{2-}\right]_{\mathrm{f}} \mathrm{lm}$ or $\left.\log \left[\mathrm{HCO}_{3}^{-}\right]_{\mathrm{f}}\right]_{\mathrm{m}}$ vs. $\log \left[\mathrm{CO}_{2}\right]_{\text {sample }}$ data points for each $\mathrm{CO}_{2}$ concentration range. ${ }^{b}$ Values given assume internal carbonate-responsive membrane electrode has Nernstian slope of $295 \mathrm{mV} /$ decade ${ }^{c}$ Values given assume internal hydrogencarbonate-responsive membrane electrode has Nernstian slope of $59 \mathrm{mV} /$ decade. 
Nernstian response properties. However, at this lower initial $\mathrm{pH}$, much lower equilibrium concentrations of carbonate ions are formed in the film and these levels are below the detection limits of the internal carbonate-responsive polymer membrane electrode [10]. Therefore, the Bis-Tris buffer cannot be utilized to prepare a carbonate membrane-based $\mathrm{CO}_{2}$ sensor that possesses acceptable detection capabilities.

The data shown in Fig. 5B and Table 3 suggest that the potentiometric detection of hydrogencarbonate ion concentrations in the thin film would greatly improve the analytical performance of the new $\mathrm{CO}_{2}$ sensor design. This would be particularly true when the Bis-Tris buffer system is used as the internal electrolyte. Use of such a buffer in conjunction with a hydrogencarbonate-responsive polymer membrane electrode would insure Nernstian detection of $\mathrm{CO}_{2}$ to concentrations $\geqslant 10^{-3} \mathrm{M}$. Moreover, because a hydrogencarbonate membrane electrode would exhibit slopes of $59 \mathrm{mV} /$ decade, the final gas sensor would be more sensitive to variations in $\mathrm{CO}_{2}$ concentrations. This approach has recently been demonstrated in a Japanese patent [16] and further work in this direction is now in progress in this laboratory.

Regardless of the type of internal sensing element (carbonate or hydrogencarbonate), the theoretical detection limits of these new $\mathrm{CO}_{2}$ sensors are determined by three parameters: (a) the initial $\mathrm{pH}$ of the buffer electrolyte, (b) the species composition of the buffer electrolyte, and (c) the ionic strength of the buffer. The initial $\mathrm{pH}$ of the buffer controls the equilibrium concentrations of carbonate and hydrogencarbonate in the thin film (see Fig. 5) and it is therefore desirable to utilize an initial $\mathrm{pH}$ which strongly favors the formation of the electro-detectable species (i.e., a good buffer trap effect). The anionic composition of the internal buffer also plays an important role in evaluating the theoretical detection limits for the $\mathrm{CO}_{2}$ sensor. Indeed, selectivity coefficients for the carbonate and hydrogencarbonate membrane electrodes over common buffer anions (e.g., chloride, phosphates, etc.) determine how low the inner sensing element can detect the ionic forms of $\mathrm{CO}_{2}$ in a given buffer reagent. It is for this reason that Tris $-\mathrm{H}_{2} \mathrm{SO}_{4}$ rather than Tris- $\mathrm{HCl}$ buffers were used in the development of carbonate electrodebased $\mathrm{CO}_{2}$ sensor [10]. In addition, as mentioned earlier for the ammonia sensor, the total initial ionic strength of the internal buffer also affects detection limits by decreasing the activity coefficients of the measured thin-film species and consequently their activities. Therefore, while high ionic strength buffers are required for more favorable Nernstian response ranges, these buffers will decrease the theoretical detection limits of the sensor. In principle, the above parameters will determine the detection limits of the $\mathrm{CO}_{2}$ sensors only when the sensors are used in a $\mathrm{CO}_{2}$-free environment. In practice, under normal measurement conditions, ambient levels of $\mathrm{CO}_{2}$ in equilibrium with the internal and sample solutions will dictate the lower limit of $\mathrm{CO}_{2}$ response and it has been reported that this level is typically $1-3 \times 10^{-5}$ $M$ [17]. Examination of Fig. 5A and the present observations with the carbonate membrane-based $\mathrm{CO}_{2}$ sensor support this view. For example, from 
Fig. 5A, the background level of $\mathrm{CO}_{2}$ in solution originating from ambient levels will produce approximately $1 \times 10^{-4} \mathrm{M}$ carbonate in the thin film (for the $0.14 \mathrm{M}$ Tris $-\mathrm{H}_{2} \mathrm{SO}_{4}$ buffer). This level is within the detection capabilities of the internal polymer carbonate electrode when evaluated separately in the same buffer reagent.

The selectivities of the new polymer membrane-based $\mathrm{CO}_{2}$ sensors are also dependent on two parameters: (a) the selectivity of the internal carbonate or hydrogencarbonate membrane electrode over anionic forms of acidic molecules capable of diffusing through the outer gas-permeable membrane, and (b) the effect of diffusing acids on the $\mathrm{pH}$ of the thin-film buffer. The former mechanism yields positive errors in the measurement of $\mathrm{CO}_{2}$ while the latter causes a negative interference in much the same way that volatile amines affect the new ammonia sensor [13]. The negative interference can be diminished to some degree by using higher ionic strength internal buffers. The positive interference can be overcome only through the development of more selective carbonate or hydrogencarbonate polymer membrane electrodes. For example, salicylic acid would be a major interferent for the carbon dioxide sensor prepared with the carbonate-responsive polymer membrane electrode. This is because the internal carbonate-responsive membrane lacks selectivity over salicylate and this anion would be formed in the thin film as salicylic acid permeates the outer gas-permeable membrane. Indeed, it has recently been shown that such nonvolatile acids can readily diffuse through the silicone rubber membranes often used to fabricate $\mathrm{CO}_{2}$ sensors [18]. Therefore, a more selective internal electrode is needed to eliminate this problem.

\section{CONCLUSIONS}

It is clear from the models presented that the optimum internal buffer electrolyte used in polymer membrane electrode-based gas sensors will vary depending on the situation. For Nernstian response over a wide concentration range, the internal buffer must have high buffer capacity toward the diffusing analyte gas so that the $\mathrm{pH}$ of the thin sensing film remains essentially unchanged. Similarly, high ionic strength buffers are required to eliminate negative interferences caused by acidic or basic species which can diffuse through the outer gas-permeable membrane. Unfortunately, the use of these concentrated internal buffer reagents has adverse effects on the detection limits of the sensors. Absolute theoretical detection limits can be extended by using buffers with initial $\mathrm{pH}$ values that are significantly different from the $\mathrm{p} K_{\mathrm{a}}$ of the analyte gas (large buffer-trap) although this approach often results in limited measurement ranges.

Aside from the $\mathrm{CO}_{2}$ and $\mathrm{NH}_{3}$ sensors modeled here, the development of other polymer membrane electrode-based probes seems highly probable. These may include: (a) a nitrogen dioxide sensor based on an internal polymeric nitrate-selective electrode, and (b) a sulfur dioxide sensor based on an 
internal bisulfite-responsive polymer membrane. In each case, the internal buffer electrolyte will have to be judiciously chosen so that optimum performance is obtained. The models and discussions presented in this report should aid in the ultimate development of these new probes.

The authors gratefully acknowledge the National Institutes of Health (Grant GM 28882-01) for supporting this work.

\section{REFERFNCFS}

1 M. Riley, in A. K. Covington (Ed.), Ion-Selective Electrode Methodology, Vol. II, CRC Press, Boca Raton, FL, 1979, Ch 1.

2 M. E. Meyerhoff and Y. M. Fraticell, Anal. Chem., 54 (1982) 27R

$3 \mathrm{G}$ J. Moody and J. D. R. Thomas, in H. Freiser (Ed.), Ion-Selective Electrodes in Analytical Chemistry, Vol. I, Plenum, New York, 1978, Ch. 6.

4 M. Mascini and C. Cremisini, Anal. Chım. Acta, 97 (1978) 237.

5 E H. Hansen and N. R. Larsen, Anal. Chim. Acta, 78 (1975) 459.

6 P. L. Bailey and M. Riley, Analyst, 102 (1977) 212.

7 J. W. Ross, J. H. Riseman and J. A. Krueger, Pure Appl. Chem, 35 (1973) 473.

8 M. E. Meyerhoff, Anal. Chem., 52 (1980) 1532.

9 M. E. Meyerhoff and R. H. Robins, Anal. Chem., 52 (1980) 2383.

$10 \mathrm{~J}$. Greenberg and M. E. Meyerhoff, Anal. Chim. Acta, 141 (1982) 57.

11 M. E. Meyerhoff, Y. M. Fraticelli, J. A. Greenberg, J. Rosen, S. J. Parks and W. N. Opdycke, Clin. Chem., 28 (1982) 1973.

$12 \mathrm{~W}$ N. Opdycke, S. J. Parks and M E. Meyerhoff, Anal Chim Acta, (1983) in press.

13 Y. M. Fraticelli and M. E. Meyerhoff, Anal. Chem., 53 (1981) 1857.

14 D G. Peters, J M. Hayes and G. M. Hieftje, Chemical Separations and Measurements, Saunders, Philadelphia, PA, 1974, Ch. 3.

15 D Midgley and K. Torrance, Analyst, 97 (1972) 626.

16 Agency of Industrial Sciences and Technology, Jpn. Pat. No. 57, 154, 048, Sept. 22, 1982.

17 U. Fiedler, E H. Hansen and J. Råžizka, Anal. Chim. Acta, 74 (1975) 423.

18 R. K. Kobos, S. J. Parks and M. E. Meyerhoff, Anal. Chem., 54 (1982) 1976. 